\title{
Sensitivity analysis of air-intake temperature on the performance of a gasoline engine of Daewoo prince $(1800 \mathrm{cc})$
}

\author{
Hayder Mnati ${ }^{1}$, Asaad Almayyahi ${ }^{2}$ and Mudhar Al-Obaidi ${ }^{1}$ \\ \{hhadermtm@mtu.edu.iq ${ }^{1}$, o811ubad6j@gmail.com ${ }^{2}$, \\ dr.mudhar.alabedt@mtu.edu.iq $\left.{ }^{1}\right\}$ \\ ${ }^{1}$ Middle Technical University, Technical Institute of Baquba, Baquba, Dayala-Iraq \\ ${ }^{2}$ General Directorate of Vocational Education, Al Hartha Industrial School-Iraq
}

\begin{abstract}
The gasoline engine and especially the four-stroke engine can be considered as one of the best and well-known engine brands that attracted the interest of consumers due to its effectiveness compared to other alternative engine types. The current study has experimentally investigated the performance and fuel economy of the gasoline engine at various intake air temperatures. In this work, a four-cylinder gasoline engine of Daewoo prince $(1800 \mathrm{cc})$ was selected. The air intake temperature was taken between $40{ }^{\circ} \mathrm{C}$ to 58 ${ }^{\circ} \mathrm{C}$ at a constant speed and load gasoline. The results confirmed that an increase in the air intake temperature causes incomplete combustion that is associated with an increase in fuel consumption. Therefore, there was a noticeable increase in fuel consumption at increased air intake temperature with an advanced and shorter combustion duration.
\end{abstract}

Keywords: Gasoline engine, Sensitivity analysis, Air-intake temperature, Fuel consumption

\section{Introduction}

The internal combustion engine is characterised by converting chemical energy into mechanical energy. This is a very fast oxidising process, which chemically merges fuel and oxygen in an atmospheric air pressure that discharges massive heat energy [1]. In other words, this process burns all combustible components in the fuel by merging oxygen with carbon and hydrogen. Hosting more air into the air-fuel mixture would advance the efficiency of combustion and boost the engine performance. Simply, the ignition incident is an engine operation period where the charge ignites and speedily oxidises through the chemical reaction to discharge heat energy $[2,3]$. Therefore, efficient combustion would completely burn all the combustible chemical constituents in the fuel. In the same context, incomplete combustion is recognised when there is unburned fuel or left constituents. Equation (1) describes the consequence of incomplete combustion such as $\mathrm{C}, \mathrm{H}_{2}, \mathrm{CO}$, or $\mathrm{OH}$ [4]

$\mathrm{CH} 4+2(\mathrm{O} 2+3.76 \mathrm{~N} 2)$ $\mathrm{CO} 2+2 \mathrm{H} 2 \mathrm{O}+7.52 \mathrm{~N} 2$

In other words, a high-performance engine of a complete mixing process can significantly limit exhaust emissions. This is attributed to the existence of closed-loop control for the fuel injection unit that aids to regulate the quantity of injected fuel considering the limited volume of intaking air. However, the air intake temperature can be considered as an alternative option to significantly improve the engine performance and fuel consumption as referred by George 
and Patterson [5]. This is basically because of air temperature on the oxygen concentration of the air charged into the system that influences the combustion process through ignition delay and fuel burning rate. It is affirmed that the colder air is denser than hotter air and contains a high amount of oxygen. Several experimental studies can be found in the open literature that investigated the impact of air intake temperature on the performance of several types of gasoline engines. For instance, Kamil and Bakar [6] and Taylor and Fayette [7] explored the simplest way to improve the engine performance by changing the air intake temperature to reduce the fuel consumption at lower exhaust emissions. Abdullah et al. [8] studied the influence of air intake temperature variation between $20^{\circ} \mathrm{C}$ to $30^{\circ} \mathrm{C}$ on the performance indicators of naturally aspirated gasoline engines $(1.6 \mathrm{~L})$ include the fuel consumption and exhaust emissions at variable engine speeds and fixed load. The experimental data confirmed the growth of the fuel consumption and the emission of unburned hydrocarbons (UHCs) and carbon monoxide (CO) emissions as a result of increasing air intake temperature.

The main target of this study is to classify the best features of air intake temperature for a selected four-cylinder gasoline engine of Daewoo prince $(1800 \mathrm{cc})$ that can fulfil a high-efficient engine performance at the possible low fuel consumption. This will be addressed by allocating the fuel consumption of the selected gasoline engine at a specified air intake temperature. Therefore, several experiments were carried out on the air intake system in an appropriate and protected environment to secure less polluted air.

\section{Experimental setup and procedure}

This section is devoted to measuring the performance indicators of a four-cylinder gasoline engine type Daewoo prince $(1800 \mathrm{cc})$ water-cooled at a fixed power and operating time as a result to varying the air intake temperature between $40{ }^{\circ} \mathrm{C}$ to $58{ }^{\circ} \mathrm{C}$. The measuring of the fuel consumption, density of the intake air, mass flow rate of intake air, and mass flow rate of fuel are considered for each run. The intake air temperature and humidity are measured using a hydro-thermometer. This is specifically carried out via the use of a sensor positioned near the air filter. However, the atmospheric pressure is assumed constant throughout the entire experiment. Also, the spark plug and filter are continuously cleaned to maintain engine consistency. Figure 1 demonstrates the schematic diagram of the gasoline engine while Table 1 reports the main characteristics of the deployed engine. 


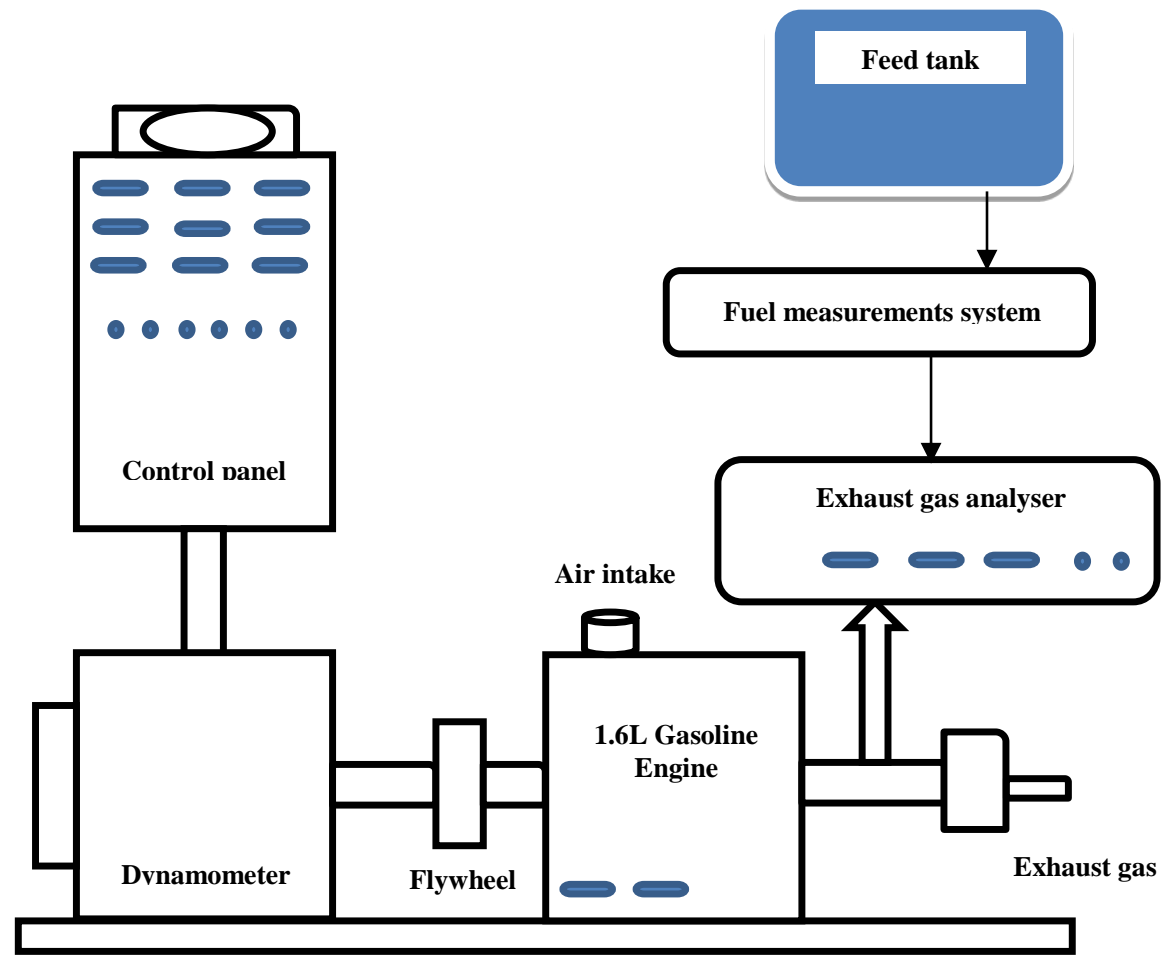

Fig. 1. Schematic diagram of four-cylinder four-stroke gasoline engine

Table 1. Specification of the four-cylinder four-stroke engine

\begin{tabular}{|l|l|}
\hline Model and make & Daewoo prince/South Korea \\
\hline General & Four-stroke/Spark ignition \\
\hline Number of cylinders & Four-inline engine \\
\hline Displacement & $1800 \mathrm{cc}$ \\
\hline Bore (diameter of each cylinder) & $84.8 \mathrm{~mm}$ \\
\hline Stroke & $79.5 \mathrm{~mm}$ \\
\hline Diameter of orifice & $55 \mathrm{~mm}$ \\
\hline Max power & $80 \mathrm{kw}$ \\
\hline Max. Rpm & 5400 \\
\hline Fuel system & Injection \\
\hline Cooling & Water \\
\hline
\end{tabular}




\section{Modelling of fuel consumption at different air intake temperatures}

Modelling of any industrial process especially gasoline engine is important to conceive the influence of operating conditions on the process performance metrics. This section exhibits a set of simple equations that have been used to characterise the calculation of air mass flow rate, air density, fuel mass flow rate, and fuel consumption.

The air mass flow rate $\left(m a^{0}\right)(\mathrm{kg} / \mathrm{s})$ of the engine is calculated by Eq.1

$m a^{0}=A a c d \sqrt{2 \rho_{a}\left(p_{1}-p_{2}\right)}$

$A a\left(\mathrm{~m}^{2}\right)$ is the fixed area of the air intake orifice of the engine as illustrated in Eq. 2

$A a=\frac{\pi}{4} d^{2}$

$d(\mathrm{~m})$ is the diameter of the orifice of the engine. $c d$ is the coefficient of discharge unit (-), $\rho_{a}$ $(\mathrm{kg} / \mathrm{m} 3)$ is the air density

$\rho_{a}=\frac{p_{1}}{R T}$

$p_{1}$ and $p_{2}$ are the manometer pressure of the engine (atmospheric pressure), and manometer pressure of the air intake, respectively. $R$ is the real gas constant ( $\left.\mathrm{atm} \mathrm{cm}^{3} / \mathrm{mole} \mathrm{K}\right)$, and $T(\mathrm{~K})$ is the absolute temperature.

Fuel mass flow rate $\left(m f^{o}\right)(\mathrm{kg} / \mathrm{s})$ is calculated based on Eq. 4

$m f^{o}=\rho_{f} \frac{v}{t}$

$\rho_{f}, v$, and $t$ are the fuel density $\left(\mathrm{kg} / \mathrm{m}^{3}\right)$, volume of consumed fuel $\left(\mathrm{m}^{3}\right)$, and operating time (s), respectively. In this regard, fuel consumption has been basically calculated from the consumed volume of fuel divided by the operating time.

\section{Results and discussion}

Table 2 presents a set of experimental data that demonstrate the variation of air intake temperature between 40 to $58^{\circ} \mathrm{C}$ at a fixed speed engine of $1500 \mathrm{rpm}$ with the calculation of air density, air mass flow rate, fuel mass flow rate, and fuel consumption at a fixed operating time of $60 \mathrm{~s}$ for each experiment. It is important to mention that the above calculations were made at specific assumptions of fixed fuel density and fixed air intake pressure of $876.5 \mathrm{~kg} / \mathrm{m}^{3}$ and 1 atmosphere, respectively. These assumptions are plausible because these parameters were insignificantly changed along with the considered variation of air intake temperature. 
Table 2. The experimental data of the Daewoo prince engine at fixed $1500 \mathrm{rpm}$ of speed engine

\begin{tabular}{cccccc}
\hline $\begin{array}{c}\text { Experiment } \\
\text { No. }\end{array}$ & $\begin{array}{c}\mathrm{T} \\
\left(\mathrm{C}^{\mathrm{o}}\right)\end{array}$ & $\begin{array}{c}\rho_{a} \\
\left(\mathrm{~kg} / \mathrm{m}^{3}\right)\end{array}$ & $\begin{array}{c}m a^{0} \\
(\mathrm{~kg} / \mathrm{s})\end{array}$ & $\begin{array}{c}m f^{o} \\
(\mathrm{~kg} / \mathrm{s})\end{array}$ & $\begin{array}{c}\text { Fuel } \\
\text { consumption } \\
(\mathrm{L} / \mathrm{hr})\end{array}$ \\
\hline 1 & 40 & 1.127 & 0.0813 & 0.0009 & 3.72 \\
2 & 43 & 1.117 & 0.0809 & 0.00092 & 3.78 \\
3 & 45 & 1.11 & 0.0807 & 0.00093 & 3.84 \\
4 & 47 & 1.103 & 0.0804 & 0.00094 & 3.9 \\
5 & 48 & 1.099 & 0.0803 & 0.00096 & 3.96 \\
6 & 50 & 1.093 & 0.0801 & 0.00099 & 4.08 \\
7 & 53 & 1.082 & 0.0797 & 0.00102 & 4.2 \\
8 & 55 & 1.076 & 0.0794 & 0.00105 & 4.32 \\
9 & 56 & 1.073 & 0.0793 & 0.00109 & 4.5 \\
10 & 58 & 1.066 & 0.0791 & 0.00112 & 4.62 \\
\hline
\end{tabular}

A detailed discussion of the influence of air intake temperature on the air density, air mass flow rate, and fuel consumption is detailed in the next sections.

\subsection{Air density}

Air density is an important engine performance indicator. Basically, it is dependent on several parameters such as temperature and humidity. The air density values at different air intake temperatures are calculated using Eq. 3. In this regard, Table 2 affirmed that air density decreases with the increase of air intake temperature of a gasoline engine. More specifically, Figure 2 shows a steady-state reduction of air density as a result of an increase in air intake temperature. Increasing air temperature would increase the maturity of air particles and increase the space between them which may interpret the reduction of a number of particles per cubic meter, i.e., decreases the air density.

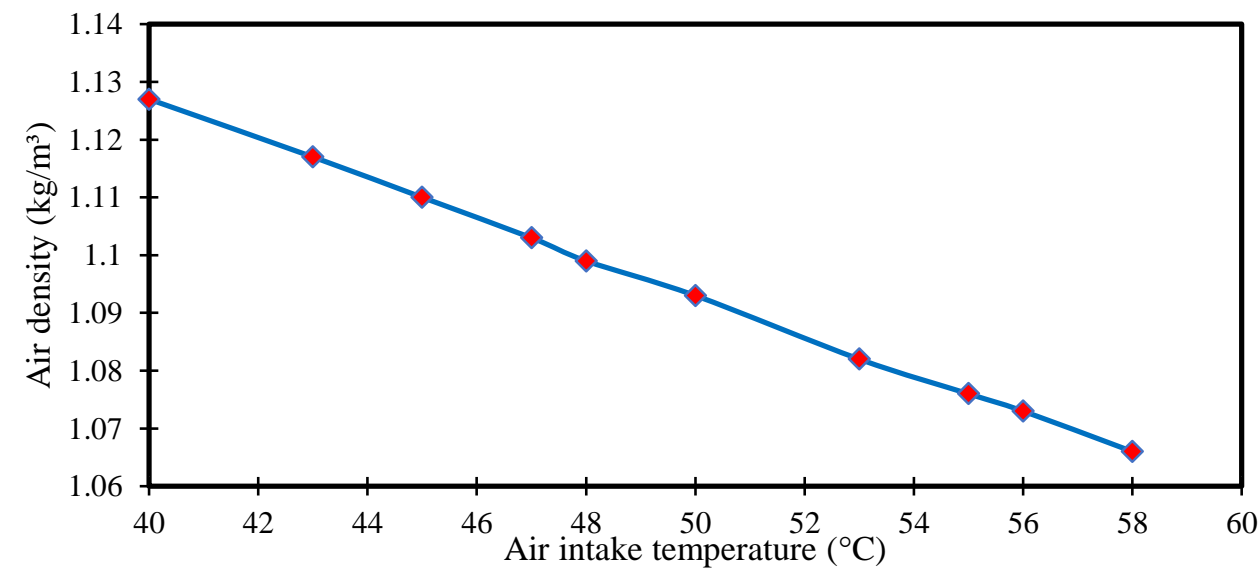

Fig. 2. Air intake temperature against air density 


\subsection{Air mass flow rate}

Air mass flow rate was measured in $\mathrm{kg}$ per cubic meter of the engine at different air intake temperatures. Figure 3 depicts a noticeable decrease in the air mass flow rate due to increasing air intake temperature between $40{ }^{\circ} \mathrm{C}$ to $58^{\circ} \mathrm{C}$. This phenomenon can be attributed to the existence of lower oxygen concentration at higher temperatures. Taylor and Fayette [7] indicated that increasing of air intake temperature of the gasoline engine would create more placing between the gas molecules at fixed operating pressure. This means a higher air volume that entails increasing air temperature, which consequently results in reduced overall air mass flow rate across the sensor. Therefore, it is fair to claim the reduction of air mass flow rate as a result of increasing the air intake temperature.

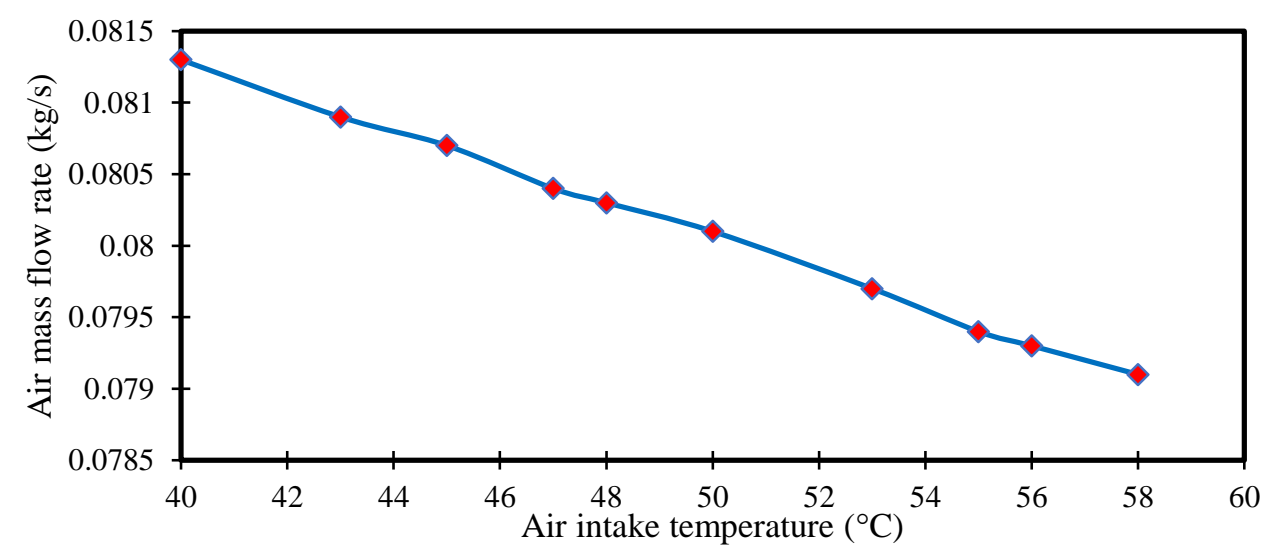

Fig. 3. Air mass flow rate against the air intake temperature

\subsection{Fuel consumption}

Fuel consumption is another fundamental engineering indicator of engine performance, which is directly related to volumetric fuel saving. Fuel consumption can be defined as the amount of consumed fuel for driving a given distance. This parameter has been calculated using a graded cylinder for a specified operation time.

The impact of increasing air intake temperature on the fuel consumption of gasoline engines can be seen in Figure 4. This showed a decrease in fuel consumption as a result of increasing the air intake temperature. This would confirm that lower air intake temperature delivers more oxygen to be joined with fuel components, which improved the combustion process of lower fuel consumption. Therefore, it is fair to mention that applying a lower air intake temperature can increase the engine performance better than a higher air intake temperature. 


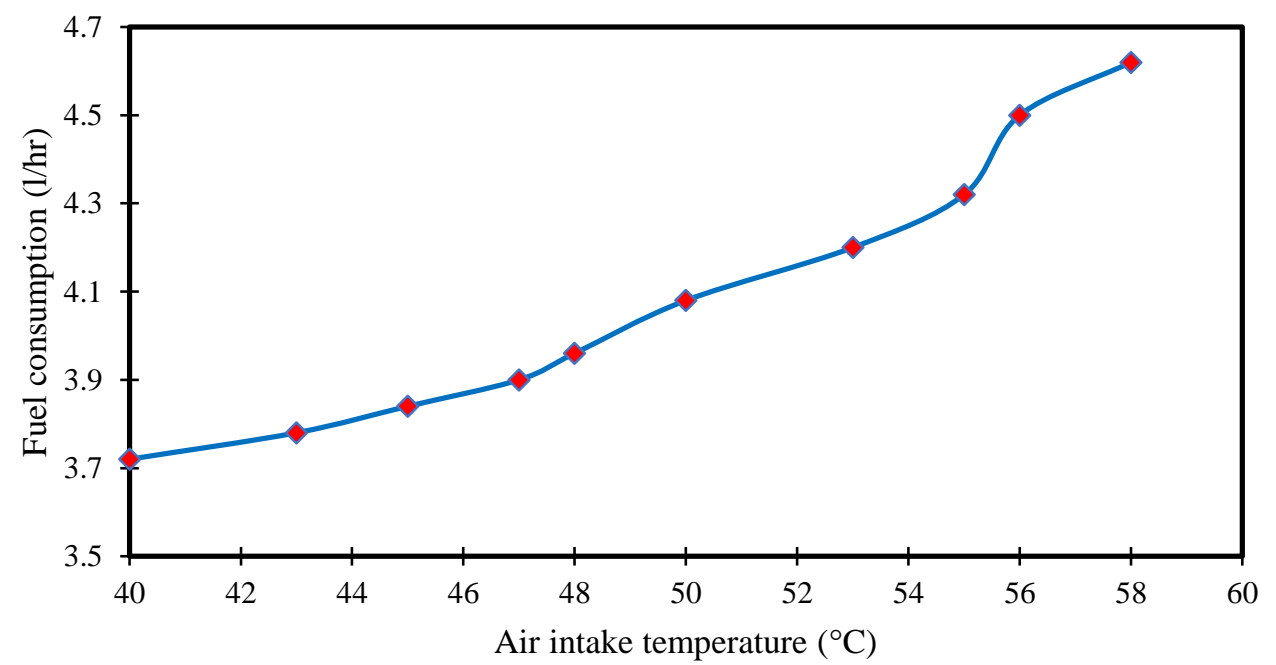

Fig. 4. Air intake temperature against the fuel consumption

Interestingly, any decrease in the air intake temperature would increase the air mass flow rate (higher oxygen concentration) as can be seen in Figure 3. Undoubtedly, the increase of charged air temperature will reduce the concentration of oxygen in the air that affects the combustion process by delaying the ignition and fuel burn rate. This is specifically compared to a higher oxygen concentration at the lower air intake temperature, which causes a complete mixing process and complete combustion. Therefore, lower fuel consumption is confirmed at a lower air intake temperature as presented in Figure 5. Therefore, a higher oxygen concentration at a low air intake temperature leads to a complete mixing process and complete combustion. Therefore, a lower air intake temperature results in improved and reduced fuel consumption. Up to this point, it is concluded that there is a significant and direct correlation between fuel consumption and air-fuel ratio. The current results corroborate the whole findings of Abdullah et al. [8] who experimentally concluded that lower air intake temperature would result in reduced fuel consumption of $1.6 \mathrm{~L}$ gasoline engines. 


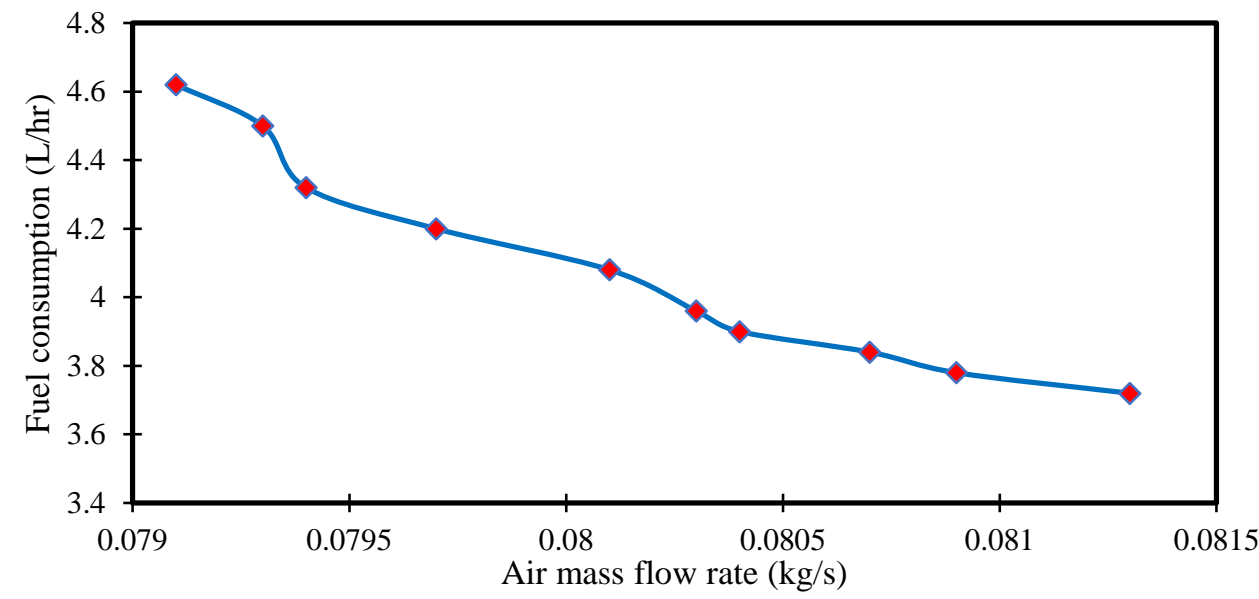

Fig. 5. Fuel consumption against the air mass flow rate

\section{Conclusions}

This research focused on experimentally studying the effect of air intake temperature on the engine performance, and fuel consumption of a four-cylinder gasoline engine of Daewoo prince $(1800 \mathrm{cc})$. In this regard, the tests were performed at fixed engine speed and engine load with different air intake temperatures between $40{ }^{\circ} \mathrm{C}$ to $58^{\circ} \mathrm{C}$. The results confirmed an increase in fuel consumption due to a decrease in air intake temperature. Specifically, the lowest value of specific fuel consumption dominantly occurred at $40{ }^{\circ} \mathrm{C}$ of air intake temperature. This is attributed to higher combustion at lower air intake temperature of higher oxygen concentration compared to a higher air intake temperature. Moreover, other important variables were measured to systematically interpret this behavior such as air density, air mass flow rate, and fuel mass flow rate besides the fuel consumption. These variables are apparently decreased when the temperature of the inlet air increases. Therefore, it can be concluded that a lower air intake temperature would improve the fuel economy by hosting a leaner air-fuel mixture. In other words, the cold air is denser and contains a large amount of oxygen that showed rich combustion. Thus, it is recommended to control the air intake temperature to mitigate the fuel consumption of gasoline engines.

\section{References}

[1] Saber, H.A., Al-Barwari, R.R.I. and Talabany, Z.J.: Effect of ambient air temperature on specific fuel consumption of naturally aspirated diesel engine. Journal of science and engineering, 1(1), 1-7 (2013).

[2] Radcliff, R., Roark, L., and Koloski. R.: Small engines, 3 ed., American Technical Publishers (2009) [3] Abdullah, N.R., Mamat, R., Rounce, P., Tsolakis, A., Wyszynski, M.L. and Xu, H.M.: Effect of injection pressure with split injection in a V6 diesel engine (No. 2009-24-0049). SAE Technical Paper (2009). 
[4] Baker, P. and Najafi, G.: The effect of methanol-diesel blended ratio on engine performance. International Journal of Automotive and Mechanical Engineering, 8, 1385-1395 (2013).

[5] George, S., Patterson, D.: Engine Emissions: Pollutant Formation and Measurement Plenum press. New York London (2013).

[6] Kamil, M., Bakar, R.A.: Performance evaluation of external mixture formation strategy in hydrogen fueled engine. Journal of Mechanical Engineering and Sciences, 1, 87-98 (2011).

[7] Taylor, B. and Fayette, C.: The internal-combustion engine in theory and practice: Combustion, fuels. Volume 2, M.I.T. press (2012).

[8] Abdullah, N.R., Ismail, H., Michael, Z., Rahim, and A.A., Sharudin, H.: Effects of air intake temperature on the fuel consumption and exhaust emissions of natural aspirated gasoline engine. Journal Teknolog, i 76(9) (2015). 